\title{
Fibroadenoma in axillary accessory breast: a case report
}

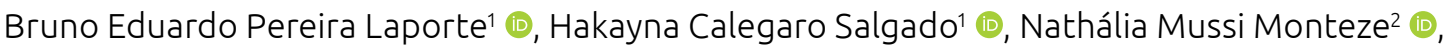

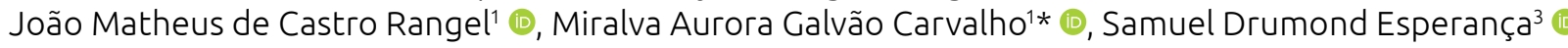

\section{ABSTRACT}

The mass are among the possible alterations observed in the axilla. When found, the most frequent differential diagnosis are lymphadenopathy, metastatic lymphadenomegaly, lymphoma, lipoma or tumors in the apocrine glands. Besides that, the presence of accessory breast tissue must also be considered and, as the topical breast tissue, can be the target of breast diseases, either benign or malignant. Female patient, 23 years old, with the presence of hardened palpable node in the right axilla. At the ultrasound, it presented characteristics that classified it as Bi-Rads ${ }^{\circledR} 4$. An aspiration biopsy of the node was performed with fine-needle, which resulted in unsatisfying material. After the explanation of the therapeutic choices, the patient opted for the excision of the axillary node. The anatomical pathological result showed a nodular formation compatible with fibroadenoma. The occurrence of a node in the axillary region is common. However, in the vast majority of times, it is merely an inflammatory response, manifested as a lymphadenomegaly. In case of chronic mass with suspicious characteristics, it is convenient to suspect the presence of lymphoid neoplasms, locoregional metastasis of breast cancer or melanoma and alterations in accessory breast tissue. In young patients, it is important to evaluate the existence of accessory breast tissue with the presence of suspicious axillary node, because, although controversial, some authors believe that such alterations occur more frequently in these patients. Additionally, in cases of inconclusive imaging, an excision of the lesion must be performed for a definite diagnosis.

KEYWORDS: fibroadenoma; breast; general surgery.

\section{INTRODUCTION}

The mass are among the possible alterations observed in the axilla. When found, the most frequent differential diagnosis are lymphadenopathy, metastatic lymphadenomegaly, lymphoma, lipoma or tumors in the apocrine glands. Besides that, the presence of accessory breast tissue (ABT) can also be listed ${ }^{1-5}$.

The frequency of accessory breast is $5.19 \%$ in women and $1.68 \%$ in men. The most commonly affected place is the axilla (particularly its inferior portion), responding for, approximately, $60 \%$ to $70 \%$ of the cases $^{1,2}$.

This anatomical variation occurs as a result of alterations in the formation of the breast tissue during the embryonic development and appears most frequently in the milk lines, which goes from the axilla until the pubic area ${ }^{1,3}$. It can be unilateral or bilateral. In most cases, its repercussion is merely aesthetic ${ }^{4}$. The conduct regarding the $\mathrm{ABT}$ is essentially conservative, although the surgical treatment may be reserved to those situations in which it generates physical, aesthetic or emotional alterations and the patient shows the desire to remove it. However, the ABT, as the topical breast tissue, may become the target of breast diseases, either benign or malign ${ }^{2-4}$.

Among the alterations that affect the topical breast tissue, the fibroadenoma is most commonly found in the premenopausal period, being a frequent cause of mass in young women, with higher incidence from 20 to 30 years old. It manifests itself as a nodular lesion, frequently unique, movable, with slow growth. At the mammography, a homogeneous, oval and confined node is observed. ${ }^{4}$ However, at the ABT, it is a rarely described finding ${ }^{3,5}$.

Due to the small number of cases reported by the medical literature, we intended to report one case treated at the Mastology Department of the Universidade Federal de Juiz de Fora, Minas Gerais.

The study was approved by the Research Ethics Committee of Hospital Universitário da Universidade Federal de Juiz de Fora, under No. 090052/2019.

\footnotetext{
${ }^{1}$ Universidade Federal de Juiz de Fora - Juiz de Fora (MG), Brazil.

¿Universidade Federal de Minas Gerais - Belo Horizonte (MG), Brazil.

${ }^{3}$ Faculdade de Ciências Médicas e da Saúde de Juiz de Fora - Juiz de Fora (MG), Brazil.

*Corresponding author: miralvagc@gmail.com

Conflict of interests: nothing to declare.

Received on: 08/14/2020. Accepted on: 09/08/2020.
} 


\section{CASE REPORT}

Female patient at 23 years old was taken to the Mastology Service due to the emergence of a palpable node of hard consistency in the right axilla. Denies personal or family history of gynecological cancer; denies breast cancer in first-degree relatives. The patient did not present other alterations at the physical exam. An ultrasound was performed in the breasts and axilla (Figure 1), which showed a solid, irregular, heterogeneous, hypoechoic node, with indistinctive margins, with the larger axis in parallel to the skin, without post acoustic phenomenon and with central vascularization at the Doppler, in the right axilla (Figure 2). Its dimensions were $1.5 \times 0.7 \mathrm{~cm}\left(\mathrm{Bi}-\operatorname{Rads}^{\circledR} 4\right)$. The findings above mentioned discarded the hypothesis of a possible lymphadenomegaly.

The patient was, then, submitted to a fine-needle aspiration biopsy (FNAB). The material obtained and sent for analysis was unsatisfying (fixation artifacts). After the inconclusive material, it was explained the therapeutic possibilities, as well as its risks, or even investigation possibilities of the nature of the nodule, like using ultrasound-guided core needle biopsy before an excisional biopsy. The patient opted for the excision of the axillary node. The anatomical-pathological result evidenced a nodular

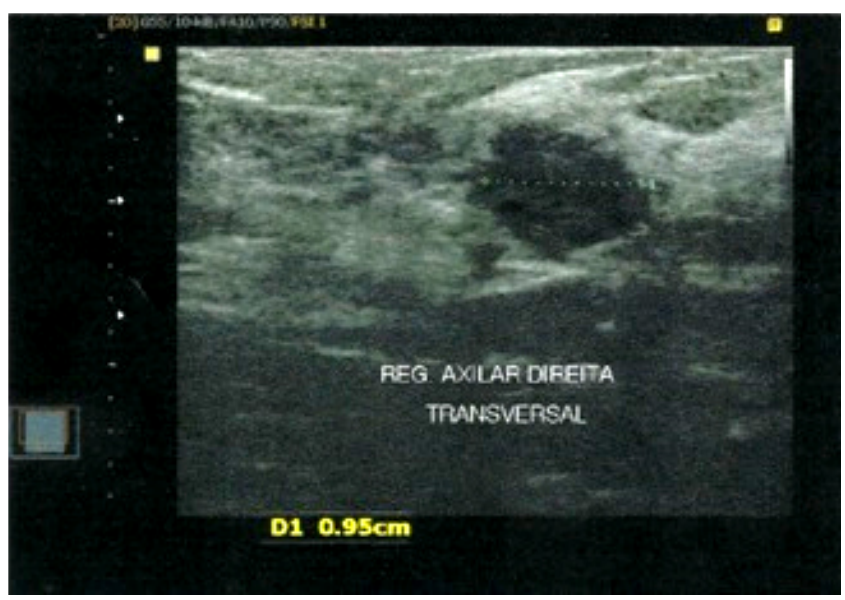

Figure 1. Ultrasonography of the right axilla.

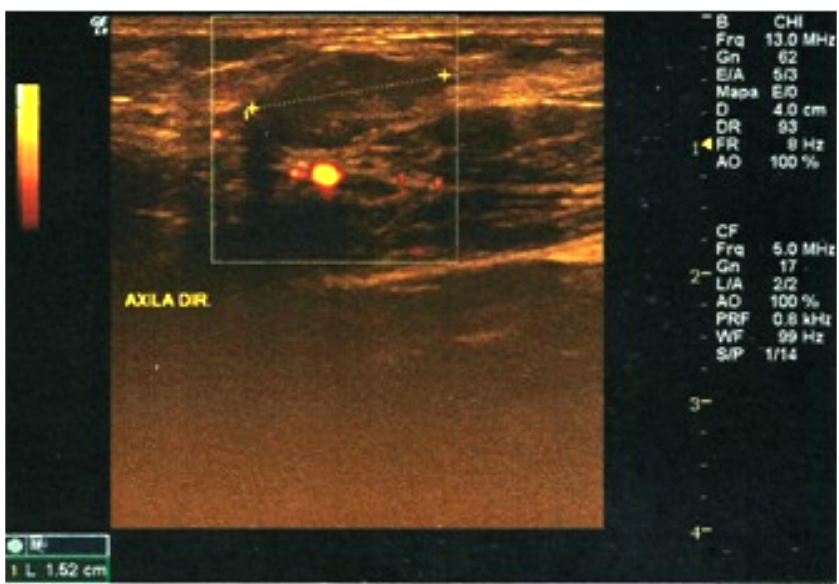

Figure 2. Ultrasonography, with Doppler effect, of the right axilla. formation of $1.9 \times 2.0 \mathrm{~cm}$, which at the microscope presented a benign and biphasic neoplasia with epithelial component constituted by ramified tubules and occasionally enlarged when at the fibroblastic stromal component, with a delicate fibrous capsule delimitating it from the adjacent breast tissue, compatible with fibroadenoma in axillary accessory breast (Figure 3).

\section{DISCUSSION}

The occurrence of a node in the axillary region is not unusual. However, at the vast majority of cases, it is merely an inflammatory response, manifested as a lymphadenomegaly. In case of chronic mass with suspicious characteristics, such as adherence to deep plans, absence of pain, irregular surface, and stony, it is convenient to suspect the presence of lymphoid neoplasms, locoregional metastasis of breast cancer or melanoma and alterations in $\mathrm{ABT}^{3}$. In this case, an adequate investigation of differential diagnostic through biochemical exams, imaging and percutaneous biopsy is necessary, having the best conduct of the patient in mind.

The presence of ABT is well documented by the medical literature; however, the presence of benign or malign tumors in this tissue is something that has been rarely reported ${ }^{3,5}$, not allowing, therefore, conclusions regarding its most common presentation form.

Table 1 summarizes a systematic search in the literature for cases involving the topic fibroadenoma in ABT filed at the PubMed. For the conclusion of the research, the following term associations were used: "fibroadenoma" and "supernumerary breast"/fibroadenoma" and "ectopic breast"/"fibroadenoma" and "axilla"/"fibroadenoma" and "axillary breast". All reports of cases of fibroadenoma in ABT with a summary available were considered and used, totalizing 19 articles, with 22 cases reported.

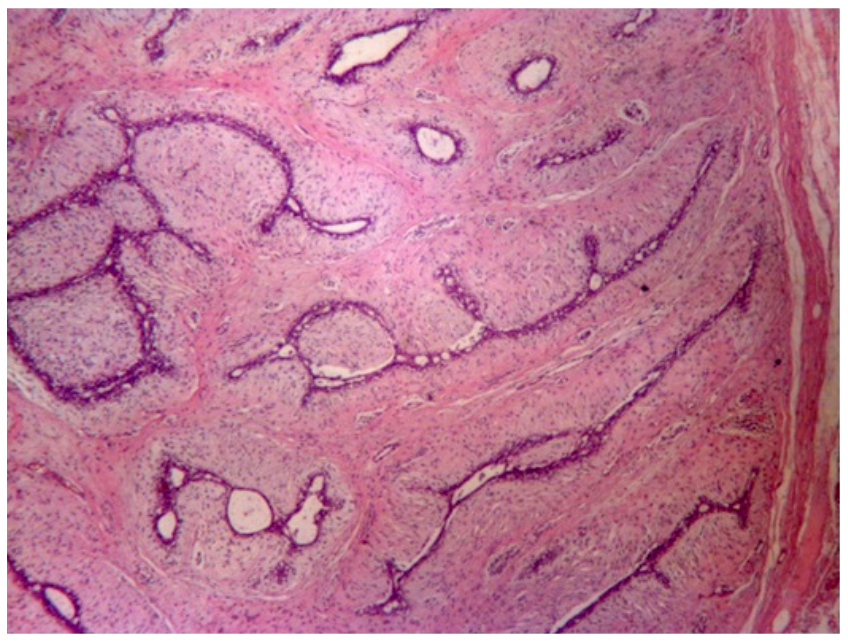

Figure 3. Benign neoplasia, biphasic, well delimited of the adjacent breast tissue through a delicate fibrous capsule. Hematoxilina-Eosina (HE) 20. 
Table 1. Reports of cases of fibroadenoma in accessory breast tissue.

\begin{tabular}{|c|c|c|c|c|c|}
\hline Year & Article & Patient's age & Site & Side & Size $(\mathrm{mm})$ \\
\hline 1982 & Khan et al. ${ }^{2}$ & 34 & Below the breast & $\mathrm{R}$ & 40 \\
\hline 1984 & Bertrand et al. ${ }^{6}$ & 80 & Urethral-vaginal Septum & ND & 20 \\
\hline 2000 & Aughsteen et al. ${ }^{7}$ & 28 & Axilla & $\mathrm{R}$ & ND \\
\hline 2002 & Baisre et al. ${ }^{8}$ & 29 and 42 & Vulva & ND & ND \\
\hline 2005 & Conde et al. ${ }^{3}$ & 39 & Axilla & $\mathrm{R}$ & 12 \\
\hline 2005 & Coras et al. ${ }^{9}$ & 23 & Axilla & $\mathrm{R}$ & $20 \times 20$ \\
\hline 2006 & Ciralik et al. ${ }^{10}$ & 23 & Axilla & ND & ND \\
\hline 2007 & Eroglu 11 & 26 & Below the breast & L & ND \\
\hline 2008 & Odike et al.12 & 34 & Axilla & $\mathrm{R}$ & ND \\
\hline 2008 & Carter et al. ${ }^{13}$ & 45 & Vulva & ND & ND \\
\hline 2009 & Cantú de Leon et al. ${ }^{14}$ & 19 & Vulva & $\mathrm{R}$ & $120 \times 50$ \\
\hline 2009 & Lucas et al. ${ }^{15}$ & ND & Vulva & ND & ND \\
\hline 2010 & Sawa et al. ${ }^{1}$ & 41 & Axilla & $\mathrm{R}$ & 38 \\
\hline 2010 & Gentile et al. ${ }^{16}$ & 58 & Axilla & Bilateral & $\begin{array}{l}50 \times 65(E) \\
55 \times 65(D)\end{array}$ \\
\hline 2011 & Zhang et al. ${ }^{17}$ & 18 & Vulva & ND & ND \\
\hline 2011 & Senatore et al. ${ }^{5}$ & 21 & Axilla & $\mathrm{L}$ & 30 \\
\hline 2012 & Ortiz-Mendoza ${ }^{18}$ & $36 \pm 9$ & Axilla & ND & $28 \pm 18$ \\
\hline 2012 & Val-Bernal et al. ${ }^{19}$ & 29 & Axilla & $\mathrm{R}$ & ND \\
\hline 2012 & Dhaoui et al. ${ }^{20}$ & 28 & Vulva & ND & $30 \times 30 \times 20$ \\
\hline 2014 & Current case & 23 & Axilla & $\mathrm{R}$ & $19 \times 20$ \\
\hline
\end{tabular}

ND: not documented. R: right; L: left.

The articles were dated from 1982 to 2012, and the average age of the patients involved in the researches was 33 years old (1830 years old). In regards to the location site of the ABT found, as well as in the patient, the most affected region is the axilla, mentioned in 10 articles (from 11 cases reported). Other locations were the vulva, mentioned in 6 articles (with 7 cases reported); the region below the breast ( 2 cases reported); the vaginal septum (1 case reported); and the anogenital region (1 case reported). The mass, similarly to our report, were most prevalent in the right side, corresponding to 9 cases of the 12 documented. The left side was reported in 2 cases, and there was 1 case of bilateral involvement. Among the mass with a description of the size, the average identified was of $3.9 \mathrm{~cm}$.

In certain cases, as in the case reported, the ABT is not clinically perceptible, making the association of a axillary node with a probable alteration of the breast parenchyma more difficult ${ }^{1,5}$.

However, at young patients, as well as in the case of the patient presented in this report, the suspicion of a ABT alteration as a result of the suspicious axillary node is very important because the accessory breast tissue, despite the controversy, may be affected by the same diseases and alterations that compromise topical breast tissue. However, due to its low incidence, diagnosis may be delayed or even ignored, thus making treatment more difficult. Then, when tumors or nodules are found along the mammary line, the presence of breast tissue should be considered during the investigation ${ }^{3,5}$.

Against the controversy about the greater chance of malignancy of the ABT and the worse prognosis, and considering the importance of the early diagnosis of breast carcinoma, surgeons are faced with the dilemma of surgical treatment or monitoring. In our case, due to the difficulties of the clinical diagnostic of $\mathrm{ABT}$ and the cytological diagnostic of fibroadenoma, the excision of the node was the choice made for the diagnostic conclusion.

\section{CONCLUSION}

Through the case report, it is possible to conclude the importance of taking into consideration the possibility of an alteration of the ABT faced with the presence of a suspicious node located in the breast line region. Additionally, in cases of inconclusive imaging and percutaneous biopsies for the diagnostic, the excision of the lesion must be performed for a definite conclusion.

\section{AUTHORS' CONTRIBUTIONS}

B.E.P.L.: Conceptualization, funding acquisition, project administration, supervision, writing - original draft, conceptualization, data curation, formal analysis, investigation, 
visualization, methodology, validation, writing - review \& editing.

H.C.S.: Conceptualization, funding acquisition, project administration, supervision, writing - original draft, conceptualization, data curation, formal analysis, investigation, visualization, validation, writing - review \& editing.

N.M.M.: Formal analysis, visualization, investigation, data curation, conceptualization, writing - original draft, methodology, validation, writing - review \& editing.
J.M.C.R.: Conceptualization, funding acquisition, project administration, supervision, writing - original draft, conceptualization, data curation, formal analysis, investigation, visualization, validation, writing - review \& editing.

M.A.G.C.: formal analysis, visualization, investigation, data curation, conceptualization, writing - original draft, methodology, validation, writing - review \& editing.

S.D.E.: formal analysis, visualization, investigation, data curation, conceptualization, writing - original draft, methodology, validation, writing - review \& editing.

\section{REFERENCES}

1. Sawa M, Kawai N, Sato M, Takeuchi T, Tamaki T, Oura S. Fibroadenoma of the axillary accessory breast: diagnostic value of dynamic magnetic resonance imaging. Jpn J Radiol. 2010;28(8):613-7. https://doi.org/10.1007/s11604-010-0466-5

2. Khan T, James CR, White JE. Tumors of extramammary breast tissue. J Natl Med Assoc. 1982;74(1):37-8.

3. Conde DM, Torresan RZ, Kashimoto E, Carvalho LEC, Cardoso Filho C. Fibroadenoma in axillary supernumerary breast: case report. São Paulo Med J. 2005;123(5):253-5. https://doi. org/10.1590/S1516-31802005000500011

4. Tiezzi DG, Valejo FAM, Nai GA, Tiezzi MG. Linfonodosentinela no câncer de mama acessória: relato de caso. Rev Bras Ginecol Obstet. 2006;28(1):50-3. https://doi.org/10.1590/ S0100-72032006000100009

5. Senatore G, Zanotti S, Cambrini P, Montroni I, Pellegrini A, Montanari E, et al. Ectopic breast fibroadenoma. Case report. G Chir. 2010;31(3):96-9.

6. Bertrand G, Deroide JP, Bidabe MC. Fibroadenoma of the paraurethral glands. A new tumoral entity? Ann Pathol. 1984;4(2):147-50.

7. Aughsteen AA, Almasad JK, Al-Muhtaseb MH. Fibroadenoma of the supernumerary breast of the axilla. Saudi Med J. 2000;21(6):587-9.

8. Baisre A, Heller DS, Lee J, Zheng P. Fibroadenoma of the vulva. A report of two cases. J Reprod Med. 2002;47(11):949-51.

9. Coras B, Landthaler M, Hofstaedter F, Meisel C, Hohenleutner U. Fibroadenoma of the axilla. Dermatol Surg. 2005;31(9 Pt 1):1152-4. https://doi.org/10.1097/00042728-200509000-00015

10. Ciralik H, Bulbuloglu E, Arican O, Citil R. Fibroadenoma of the ectopic breast of the axilla: a case report. Pol J Pathol. 2006;57(4):209-11.

11. Eroglu A. Fibroadenoma in supernumerary breast. J BUON. 2007;12(2):285-6.
12. Odike MA, Orakwe JC, Oguejiofor OC, Odenigbo UC, Onyiaorah IV. Axillary fibroadenoma mimicking lymphadenopathy. Niger J Clin Pract. 2008;11(1):72-3.

13. Carter JE, Mizell KN, Tucker JA. Mammary-type fibroepithelial neoplasms of the vulva: a case report and review of the literature. J Cutan Pathol. 2008;35(2):246-9. https://doi. org/10.1111/j.1600-0560.2007.00796.x

14. Cantú de Leon D, Perez Montiel D, Vázquez H, Hernández C, Cetina L, Lucio MH. Vulvar fibroadenoma: a common neoplasm in an uncommon site. World J Surg Oncol. 2009;7:70. https://dx.doi.org/10.1186\%2F1477-7819-7-70

15. Lucas EW Jr., Branton P, Mecklenburg FE, Moawad GN. Ectopic breast fibroadenoma of the vulva. Obstet Gynecol. 2009;114(2 Pt 2):460-2. https://doi.org/10.1097/ aog.0b013e3181af672d

16. Gentile P, Izzo V, Cervelli V. Fibroadenoma in the bilateral accessory axillary breast. Aesthetic Plast Surg. 2010;34(5):6579. https://doi.org/10.1007/s00266-010-9505-y

17. Zhang J, Chen Y, Wang K, Xi M, Yang K, Liu H. Prepubertal vulval fibroma with a coincidental ectopic breast fibroadenoma: report of an unusual case with literature review. J Obstet Gynaecol Res. 2011;37(11):1720-5. https://doi. org/10.1111/j.1447-0756.2011.01580.x

18. Ortiz-Mendoza CM. Axillary ectopic breast tissue fibroadenoma: report of three cases and review of the literature. Ginecol Obstet Mex. 2012;80(2):99-103.

19. Val-Bernal JF, González-Vela MC, De Grado M, Garijo MF. Sclerotic fibroma (storiform collagenoma)-like stroma in a fibroadenoma of axillary accessory breast tissue. J Cutan Pathol. 2012;39(8):798-802. https://doi.org/10.1111/j.16000560.2012.01940.x

20. Dhaoui A, Nfoussi H, Kchir N, Haouet S. Vulvar lactating adenoma associated to a fibroadenoma: common neoplasms in an uncommon site. Pan Afr Med J. 2012;13:47. 